\title{
Ordovician Limestone Aquifer Seepage Field Simulation Based on Modflow
}

\author{
Wei jiuchuan \\ Shandong Provincial Key Laboratory of Depositional \\ Mineralization \& Sedimentary Minerals \\ College of Geological Sciences \& Engineering in Shandong \\ University of Science and Technology \\ Qingdao, China, 266510 \\ jcwee@126.com \\ Wang Shasha, \\ Shandong Provincial Key Laboratory of Depositional \\ Mineralization \& Sedimentary Minerals \\ College of Geological Sciences \& Engineering in Shandong \\ University of Science and Technology \\ Qingdao, China, 266510
}

\author{
Yin Huiyong, \\ Shandong Provincial Key Laboratory of Depositional \\ Mineralization \& Sedimentary Minerals \\ College of Geological Sciences \& Engineering in Shandong \\ University of Science and Technology \\ Qingdao, China, 266510
}

Xie Daolei

Shandong Provincial Key Laboratory of Depositional Mineralization \& Sedimentary Minerals

College of Geological Sciences \& Engineering in Shandong

University of Science and Technology

Qingdao, China, 266510

\section{THE DRAINING TEST}

\begin{abstract}
According to the data of draining test, we simulated the Ordovician limestone aquifer seepage field by MODFLOW module of GMS (Groundwater Modeling System). After numerical simulation model building, we successfully simulated the seepage field formed by draining test and dynamic changes in the water level by model recognition and inspection. The results reflect that lateral connectivity and hydraulic connection of fissure and crevasse is weak in Ordovician limestone aquifer. The study provides theoretical base and practical references for safe mining of No.11 coal seam which is threatened by Ordovician limestone aquifer confined water.
\end{abstract}

Keywords-draining test; seepage field; MODFLOW; numerical simulation; model recognition and inspection

\section{INTRODUCTION}

In recent years, limestone Karst water inrush accidents have been $92.3 \%$ of the coal mine water disasters in China, and it is very important to prevent and to control the limestone water disasters. The main mining coal seam of Baode Coal Mine is the No.11 coal seam ${ }^{[1]}$, underlying which is the Ordovician limestone aquifer. Mining of the No.11 coal seam is great threatened by Ordovician limestone aquifer for most parts of the seam are below the aquifer water head. Thus, using GMS, we did the numerical simulation on Ordovician limestone aquifer ${ }^{[1]}$ seepage field in Baode Coal Mine to provide theoretical and techniques support for coal mining.

GMS is comprehensive graphical interface software which integrates MODFLOW, FEMWATER, MT3D ${ }^{[2]}$ module, etc. In this study, we used the MODFLOW module which can simulate steady and transient flow in aquiclude, ground water flow and confined water flow by finite difference method. It connects every step closely during the numerical simulation, and makes the whole process systematic and standardized.
This draining test was done with constant-drawdown and variable flowrate, and was observed as the unsteady flow. We used $\mathrm{f}_{1}$ and $\mathrm{f}_{2}$ as draining holes, used surface holes ( $\mathrm{g}_{4}, \mathrm{~g}_{6}$, $\mathrm{SK} 30, \mathrm{sj}_{2}, \mathrm{SK} 33$ ) and underground drilling hole $\mathrm{g}_{7}$ as the observation holes. First, continuously drained water from underground hole $f_{1}$ for one day, and observed by $f_{2}, g_{7}, g_{4}, g_{6}$, SK30, sj $\mathrm{j}_{2}$ and SK33 at the same time. Then after one whole day, we opened $\mathrm{f}_{2}$ 's sluice valve, and observed groundwater level variation by $g_{7}, g_{4}, g_{6}, S K 30, s_{2}$ and SK33 at the same time. Cone of depression formed and centered on the draining holes. In that case, we observed and probed the distribution of Karst water runoff and the direction of water supply to get the hydro-geological parameters.

This draining test last for 17 days and 7.5 hours, which contains 3 days of water level recovery. During the test, the distance between $\mathrm{g}_{4}$ and $\mathrm{f}_{1}$ was $2973 \mathrm{~m}$, and the biggest water level drop of $g_{4}$ was $0.49 \mathrm{~m}$. Water levels in $g_{6}$ and $\mathrm{sj}_{2}$ appeared intermittent fluctuations for the influence from wells pumping in gangue power plant, and water drainage in Baode Coal Mine. Water levels in $\mathrm{g}_{7}$ fell instead of rising. The pressure was $0.88 \mathrm{Mpa}$ before the test, and changed to $1.01 \mathrm{MPa}$ after three times water drawdown.

\section{NUMERICAL SIMULATION ON ORDOVICIAN LIMESTONE AQUIFER SEEPAGE FIELD}

\section{A. Conceptual hydrogeological model}

The simulation model calculation districts were the whole Baode Coalfield and its outside regions. Ordovician limestone aquifer here belongs to Tianqiao Karst Springs Area, which is in a singe inclination. There is no large scaled fault in study area. According to the seepage field features after draining, the 
location of the Yellow River, and minor faults in the north, we extended the calculation area $1500 \mathrm{~m}$ from the Coalfield boundary to all around outside, with the Yellow River as the northwestern boundary.

1) Internal structure generalization of the groundwater system

Water-bearing mediums of the Ordovician limestone aquifer in this Coalfield are dominated by solution fissures, and followed by corroded pores and caverns. The whole aquifer is buried under the coal series in the calculation area, forming a thick-bedded confined aquifer with the unified hydraulic field. For all those reasons, aquifer structure and hydrodynamic conditions in the study area can be generalized as the 2-D heterogeneous anisotropic unstable confined flow, which was supplied by overlying unconsolidated formation coal-bearing formation, atmospheric precipitation and surface water infiltration.

\section{2) Generalization of the initial condition}

Initial condition is the condition of water head distribution of every spot $(\mathrm{x}, \mathrm{y})$ in the seepage field $\mathrm{D}$ at the initial moment $(t=0)$. If we set the water head of every spot in the seepage field $\mathrm{D}$ as $\mathrm{H} 0(\mathrm{x}, \mathrm{y})$ at one moment (usually $\mathrm{t}=0$ ), then the initial condition would be as following:

$$
\left.H\right|_{t=0}=H_{0}(x, y) \quad(x, y) \in D
$$

During the numerical simulation, initial ground water seepage field should be presumed according to the measured water levels. Neuman ${ }^{[3]}(1984)$ and $\operatorname{Sun}^{[4]}(1999)$ put forward the Residual Kriging (RK) method to presume regional groundwater levels. The basic idea is to filter trend components out of groundwater levels to get residual measured water levels, then use Ordinary Kriging(OK) method to presume space distribution of the residual water levels. After that, we can get the distribution of the groundwater levels according to trend components and presumed space distributions of the residual. The RK method is easy to use and understand, but it also needs a lot of site observed data, otherwise the presumed precision may be reduced. In our study, as monitored data of Ordovician limestone aquifer water levels here was not enough, we modified the RK method according to terrain elevation and the elevation of the geological contours, and raised the presumed precision of the distribution of the groundwater levels.

Using the Ordovician limestone aquifer water levels data that gotten from the draining test on August 15, 2011, we got the initial water levels by interpolation and extrapolation method.

\section{3) Generalization of the boundary conditions}

Boundary condition processes will greatly influence the accuracy of the simulation results. So it is important to appropriately process the boundary conditions. Water discharge in the draining test was small, so influenced area was limited. Thus, we considered the influenced area and flow field characteristics from the beginning to the end of the test when we choose the simulation model boundary. To the east, west and southwest boundaries without water level change during the draining test, we set them as the first kind of boundary that was given head. Water level was constant in the northwest near the Yellow River, we set the boundary here as the first kind of boundary that was given head. We set the north boundary that bordered by minor faults as the weak flow boundary. The boundary of the simulate area is shown as Fig. 1.

\section{4) The source and sink}

Supplies of the Ordovician limestone aquifer were overlying unconsolidated formation coal-bearing formation, atmospheric precipitation and surface water infiltration. Water discharge was dominated by drainage holes draining.

\section{B. Numerical hydrogeological model}

\section{1) Mathematical model}

Based on the conceptual hydrogeological model above, that is, 2-D heterogeneous anisotropic unstable confined flow, we build the mathematical model as equation (2).

In the equation, $Q_{i}$ is water quantity of drainage hole $\left(\mathrm{L}^{3} \mathrm{~T}^{-1}\right)$, $n$ is the quantity of drainage hole, $K_{x}$ and $K_{y}$ are all osmotic coefficient $\left(\mathrm{LT}^{-1}\right), H$ is the water head(L), $h_{0}$ is initial water head $(\mathrm{L}), \mu_{s}$ is storativity of the aquifer, $t$ is duration of the test

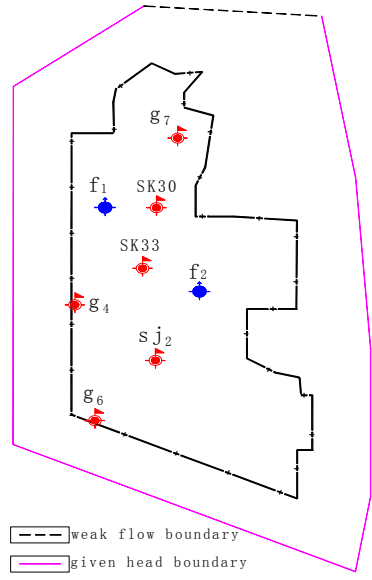

Fig. 1 The sketch map of simulate boundary

$$
\left\{\begin{array}{lr}
\frac{\partial}{\partial x}\left(K_{\mathrm{x}} \frac{\partial H}{\partial x}\right)+\frac{\partial}{\partial y}\left(K_{\mathrm{y}} \frac{\partial H}{\partial y}\right)-\sum_{i=1}^{n} Q_{i}=\mu_{\mathrm{s}} \frac{\partial H}{\partial t} \quad(x, y) \in D, t>0 \\
H(x, y, 0)=h_{0}(x, y) \quad(x, y) \in D \\
\left.H_{1}(x, y, t)\right|_{\Gamma 1}=\varphi_{1}(x, y, t) \quad(x, y) \in \Gamma_{1}, t>0 \\
\left.K \frac{\partial H}{\partial n}\right|_{\Gamma 2}=q_{2}(x, y, t) \quad(x, y) \in \Gamma_{2}, t>0
\end{array}\right.
$$

(T), $\Gamma_{1}$ is the first kind of boundary, $\Gamma_{2}$ is the second kind of boundary, $h_{0}(x, y)$ represents initial water head distribution, $\varphi_{1}$ is water head of the first kind of boundary, $q_{1}$ is water quantity of the second kind of boundary, $x$ and $y$ are the coordinates.

\section{2) Zone discretization}

We discretized zone by rectangular grid, and appropriately added grids near drainage holes and observation holes. The zone is $18684 \mathrm{~m}$ long and $9611 \mathrm{~m}$ wide, and was discretized to 103 rows, 58 columns and 5974 units, of which there were 5082 effective units. Zone discretization is shown as Fig.2. 


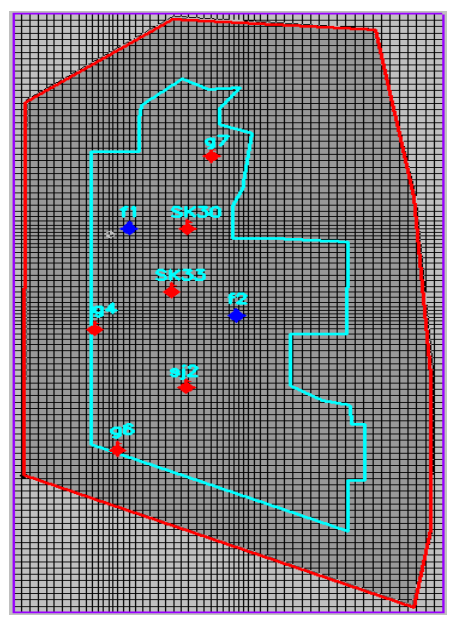

Fig. 2 Zone discretization of the simulation area

\section{3) Temporal Discretization}

The test started from 11 a.m. on August 15, 2011 to 19 p.m. on September 1, 2011, 24960 minutes in total, which contains 344 hours dewatering and 72 hours water level recovery. During the test, there were three times water level drawdowns. Water level fluctuated quite a bit in the early period of every drawdown, and became stable in the later period. So we divided periods more detailed at the early stage of flow rate variation, and extended appropriately at the later stage. There were 110 stress periods in total.

TABLE 1.

TEMPORAL DISCRETIZATION RESULTS

\begin{tabular}{|c|c|c|c|c|}
\hline $\begin{array}{c}\text { Time } \\
\text { range }\end{array}$ & $\begin{array}{c}11-8-1511: \\
00 \sim 11-8-21 \\
18: 00\end{array}$ & $\begin{array}{c}11-8-2118: \\
00 \sim 11-8-25 \\
18: 00\end{array}$ & $\begin{array}{c}11-8-2518: \\
00 \sim 11-8-29 \\
19: 00\end{array}$ & $\begin{array}{c}11-8-2919: \\
00 \sim 11-9-1 \\
19: 00\end{array}$ \\
\hline $\begin{array}{c}\text { Time } \\
\text { span/min }\end{array}$ & 9060 & 5760 & 5820 & 4320 \\
\hline $\begin{array}{c}\text { Stress } \\
\text { periods }\end{array}$ & 29 & 30 & 25 & 26 \\
\hline
\end{tabular}

\section{Recognition and inspection of hydrogeology model}

Recognition and inspection of hydrogeology model, is to quantify the model by numerical analog computation, according to transient information of artificial flow field supplied by draining test, or to normal information of natural flow field supplied by groundwater long-term observation. We use the data supplied by group drilling draining test that last from 11 a.m. on August 15, 2011 to 19 p.m. on September 1, 2011. There were many uncertainties, which caused by artificially demarcated boundary conditions and lack of informative data, and made model parametric recognition multiple solution and instability. To overcome these, we used estimation correction to solve and predict parameters, water levels and yield objective and reality. Recognized parameters are osmotic coefficient $K$ and storage coefficient $\mu^{*}$.

We used estimation correction to adjust and optimize initial estimates of every parameter repeatedly to reduce errors between simulated and measured water head on each observation holes to a minimum. Based on the built mathematical model, zone discretization and definite condition, and according to test results, structural features, aquifer properties, flow field form and water variation characteristics, we preliminary determined the upper and lower limits of every parameter as the constraint intervals of corresponding parameters.

We fitted dynamic water level measured data of observation holes to get hydrogeological parameters of aquifer. Fitting degree of water head can basically reflect the accuracy of the parameters. We set the objective function as:

$$
E\left(p_{1}, p_{2}, \cdots, p_{n}\right)=\sum_{i=1}^{m} \sum_{j=1}^{n}\left[H(i, j)-H_{g}(i, j)\right]^{2}
$$

In the equation, $p_{1}, p_{2}, \cdots, p_{n}$ are unknown hydrogeological parameters, $m$ is the number of observation holes that used to contrast water heads, $n$ is the number of period, $H(i, j)$ is the water level of spot $i$ within $j$ period(m), $H_{g}(i, j)$ is measured water level of spot $i$ within $j$ period(m).

We tried to get the minimum objective function according to constraint conditions of each parameter. If fitting difference isn't reduced to the minimum, we will repeatedly further analyzed the reason, and adjust the constraint conditions and definite conditions when it needs, until we get the minimum objective function. Finally, we reduced degree of distortion, improved the accuracy and got practical applied effect.

All the data from drainage holes and observation holes were used. Water levels from 4 observation holes were fitted, they were $g_{4}, g_{6}, s_{2}$ and SK30. Abnormal data from $g_{7}$ and SK33 were not used for fitting. The span of data fitting was the whole period of the draining test, containing water level recovery.

Simulation results shown that errors between simulated and measured water levels were between $0.01 \sim 1 \mathrm{~m}$, the relative errors were concentrated within $1 \%$.

According to National Standards of Peoples Republic of China: GB/T14497-93 Requirements for the work of groundwater resources management, the number of nodes with water level relative errors less than $10 \%$, should be more than $70 \%$ of the number of known nodes. But for the complex structure, it can be appropriately adjusted. In our simulation, relative errors of Ordovician limestone aquifer were all less than $10 \%$. So our simulation results all complied with the requirements of the National Standards, and were comparatively perfect.

Through model parametric recognition, hydrogeological parameters of the simulated area were: $K_{x}=0.000269 \mathrm{~m} / \mathrm{min}$, $K_{y}=0.000224 \mathrm{~m} / \mathrm{min}, K=0.00035 \mathrm{~m} / \mathrm{min}, \mu_{s}=0.72 \times 10^{-5} \mathrm{~m}^{-1}$ 。

Statistic errors between simulated and measured water levels were shown in table 2, and Water level fitted curves of every hole were shown as Fig.3 Fig.6.

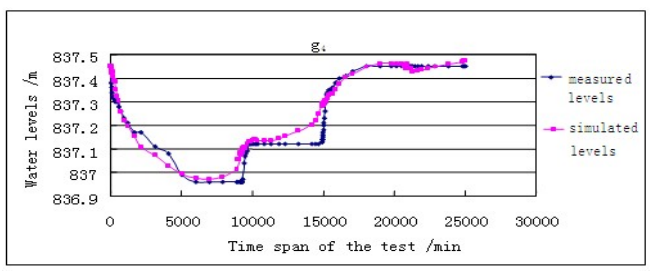

Fig.3 Water level fitted curves of $\mathrm{g}_{4}$ 


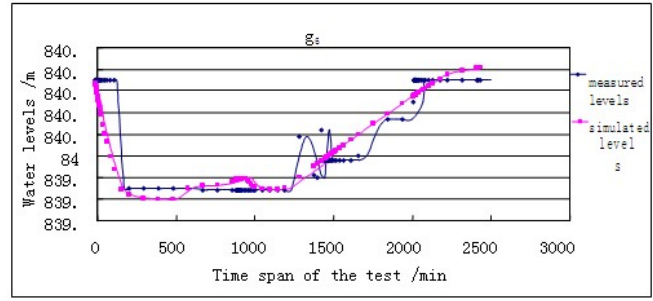

Fig.4 Water level fitted curves of $g_{6}$

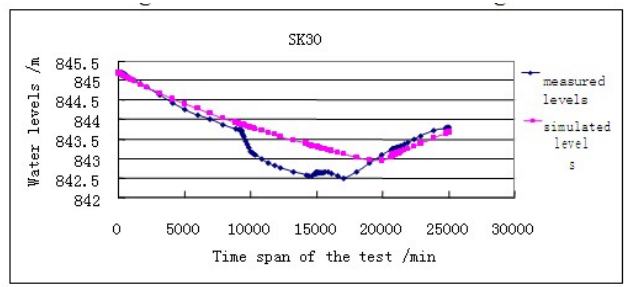

Fig.5 Water level fitted curves of SK30

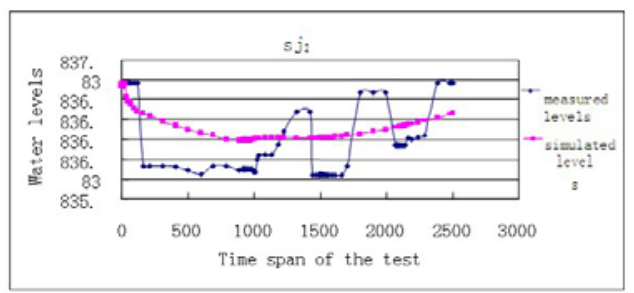

Fig.6 Water level fitted curves of $\mathrm{sj}_{2}$

TABLE $2 . \quad$ STATISTIC ERRORS BETWEEN SIMULATED AND MEASURED WATER LEVELS

\begin{tabular}{|c|c|c|c|c|c|c|}
\hline Hole & $\begin{array}{c}\text { Mean } \\
\text { absolute } \\
\text { error } / \mathbf{m}\end{array}$ & $\begin{array}{c}\text { Minimum } \\
\text { absolute } \\
\text { error } / \mathbf{m}\end{array}$ & $\begin{array}{c}\text { Maximum } \\
\text { absolute } \\
\text { error } / \mathbf{m}\end{array}$ & $\begin{array}{c}\text { Mean } \\
\text { relative } \\
\text { error/\% }\end{array}$ & $\begin{array}{c}\text { Minimum } \\
\text { relative } \\
\text { error/\% }\end{array}$ & $\begin{array}{c}\text { Maximum } \\
\text { relative } \\
\text { error/\% }\end{array}$ \\
\hline $\mathbf{g}_{4}$ & 0.3174 & 0.0071 & 0.5274 & 0.0378 & 0.000848 & 0.063 \\
\hline $\mathbf{g}_{6}$ & 0.084 & 0.0033 & 0.4136 & 0.0099 & 0.000393 & 0.049 \\
\hline $\mathbf{s j}_{2}$ & 0.3135 & 0.0086 & 0.8533 & 0.036 & 0.001 & 0.07 \\
\hline SK30 & 0.3738 & 0.007 & 0.8797 & 0.043 & 0.000828 & 0.095 \\
\hline
\end{tabular}

\section{Analysis of simulated results}

The span of data fitting was the whole period of the draining test, with 110 stress periods in total.

Seepage field of Ordovician limestone aquifer and groundwater flow direction during initial period were shown as Fig.7, those at the end of simulated period were shown as Fig.8, those at the end of three times water drawdown were respectively shown as Fig.9 Fig.10.

Comparing Fig.7 with Fig.8, seepage distribution of Ordovician limestone aquifer and groundwater flow direction changed little from beginning to end of the draining test. Groundwater flow field direction was generally the same as the direction of coal strata monoclinic. The northwest of the Coal field was near the Yellow River, with low water level, and the east and south had high water level, which made the seepage flowing from the southeast to the northwest. Water levels didn't change obviously except 2 meters falling around SK30 hole near $\mathrm{f} 1$ hole during the whole process of simulation.

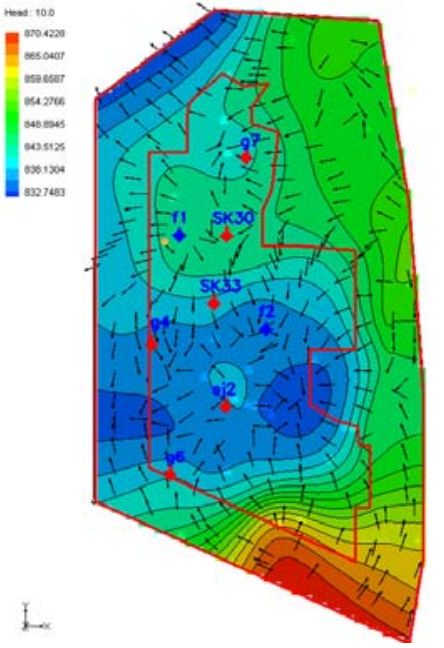

Fig.7 Ordovician limestone aquifer seepage field during initial period

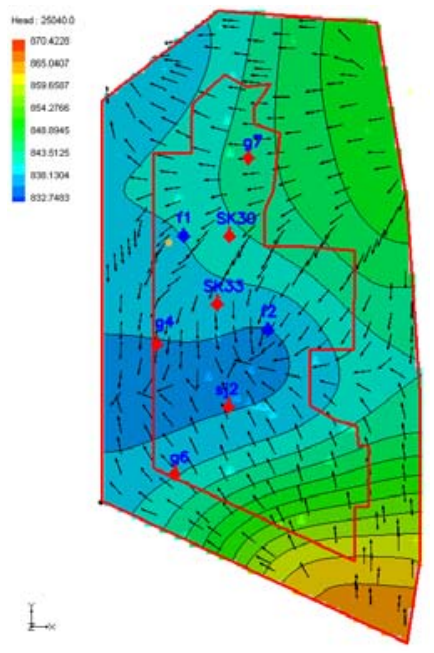

Fig.8 Seepage field at the end of the simulating period
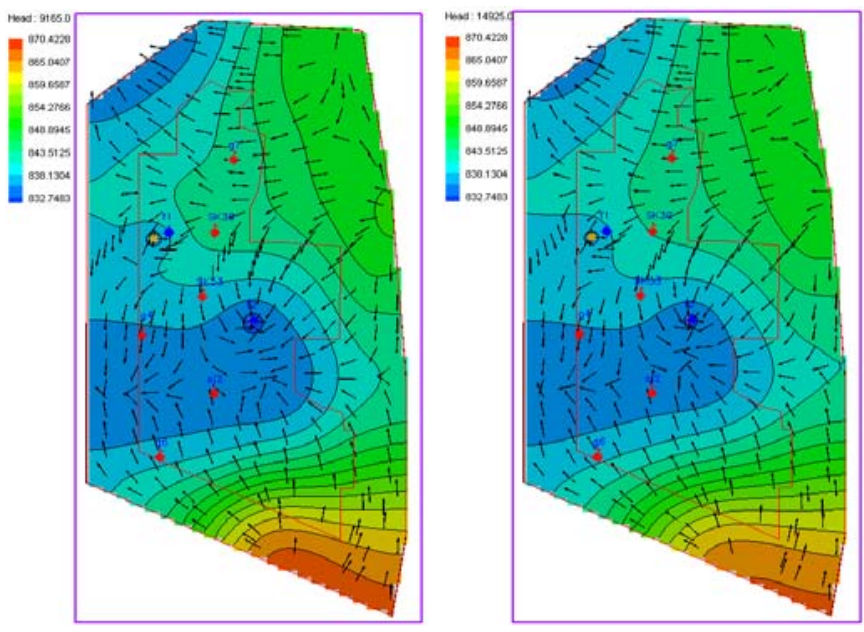

Fig.9 Ordovician limestone aquifer flow direction at the end of the first (left figure) and the second (right figure) drawdown

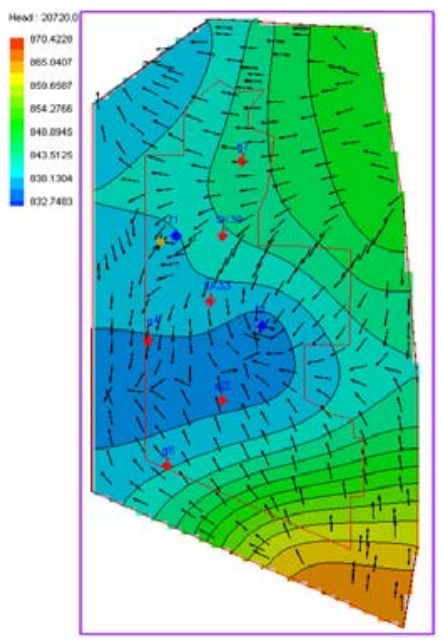

Fig.10 Ordovician limestone aquifer flow direction at the end of the third drawdown 


\section{CONCLUSION}

Our simulation results all complied with the requirements of the National Standards, and were comparatively perfect. Through model parametric recognition, we got hydrogeological parameters of the study area. Simulation results show that, seepage distribution of Ordovician limestone aquifer and groundwater flow direction changed little from beginning to end of the draining test. It reflects that lateral connectivity and hydraulic connection of fissure and crevasse is weak in Ordovician limestone aquifer.

\section{REFERENCES}

[1] Wang Shasha, Evaluation of the Ordovician limestone water enrichment and water inrush risks of the NO.11 coal seam floor in Baode Coal mine. SDUST, 2011.

[2] Ma Jing, Wu Ping and Tong Yanzhao, "Brief introduction of conceptional model method in GMS", in Science \& Technology, Information, 2011(29), pp. 512-513.

[3] Neuman, S.P. and E.A. Jacobson, Analysis of nonintrinsic spatial variability by residual kriging with application to regional roundwater levels, Math. Geol, 16(5), pp.499-521.

[4] Sun, Ne-Zheng, Inverse problems in groundwater modeling, Kluwer Academic Publishers, The Netherlands, pp.161-210. 